\title{
EXPERIMENTAL STUDY OF OPERATIONAL CHARACTERISTICS OF NEW TOP HARVESTING MACHINE
}

\author{
Volodymyr Bulgakov ${ }^{1}$, Semjons Ivanovs ${ }^{2}$, Simone Pascuzzi $^{3}$, Yevhen Ihnatiev ${ }^{4}$ \\ ${ }^{1}$ National University of Life and Environmental Sciences of Ukraine, Ukraine; \\ ${ }^{2}$ Latvia University of Life Sciences and Technologies, Latvia; ${ }^{3}$ University of Bari Aldo Moro, Italy; \\ ${ }^{4}$ Tavria State Agrotechnological University, Ukraine \\ semjons@apollo.lv,simone.pascuzzi@uniba.it
}

\begin{abstract}
In the sugar beet harvesting process the most significant technological operations are digging the root crops out of the soil and removing the uncut leaves. Field experimental studies have been carried out to determine the operational characteristics of this top harvesting machine. For this, a program and methodology for conducting such experimental studies were developed, the results of which were processed by statistical methods on a PC, using the basic methods of the regression and correlation analysis. Performance indicators have been obtained: productivity, when aggregated with a class 1.4 wheeled tractor $-2.15 \mathrm{ha} \cdot \mathrm{h}^{-1}$; specific fuel consumption $-3.02 \mathrm{~kg} \cdot \mathrm{ha}^{-1}$. The power for the process of harvesting sugar beet tops is $14.48 \mathrm{~kW}$, the traction power does not exceed $3.6 \mathrm{~kW}$. It has been established that the power required for cutting the tops is $6.0-6.2 \mathrm{~kW}$, and, to ensure transportation and loading of the cut tops into the vehicle, a power of $3.5-4.8 \mathrm{~kW}$ is needed. The obtained results of the investigations of the operational indicators of the three-row top harvesting machine, developed by us, are about 2 times smaller than in comparison with the commercially available harvesting machines.
\end{abstract}

Keywords: sugar beet, tops, cutting, aggregate, operational characteristics.

\section{Introduction}

Sugar beet is one of the important agricultural crops in many European countries [1;2]. In the sugar beet harvesting process the most significant technological operations are digging the root crops out of the soil and removing the uncut leaves [3; 4]. Sugar beet tops have good nutritional properties and can be used as feed in animal husbandry both in green form and as silage [5; 6]. In addition, sugar beet tops are now widely used as a raw material in the production of biogas, as well as organic fertiliser, which can be applied to the soil immediately after cutting and disintegrating. The top harvesting machines of a modern technical level carry out harvesting of the tops in several stages: so, at the first stage a complete cutting of the general green mass of tops without copying is carried out, its collection and transportation. At the second stage the heads of the root crops are removed from the top residues without extracting out of the soil, or the preliminary trimmed.

Widely applied in the world are toppers or frontally mounted modules of the modern beet harvesters that have a rather complicated structure. They do not collect the cut-off tops (they crush and scatter them around the field). They contain additional cutters (after-cutter) leading to insignificant losses of the sugar-bearing mass. Due to the existing deviations in the height of the heads of the root crops, there is a sharp decrease in the harvesting quality and significant losses of the green mass of the tops (which is, for example, a valuable source for biogas production) and significant energy costs for the implementation of this technological process.

They carry out the top harvesting process by top-cutting tools, individually copying the heads of root crops in each row, and then collecting and loading the tops into a vehicle. The main disadvantages in the operation of these harvesting machines are the insufficient quality of trimming the heads of root crops, the losses of tops and high operational indicators, which is especially pronounced with significant yields of tops, or significant deviations of the root crops in the rows [7; 8]. Therefore, the development of improved designs of the harvesting machines that would ensure high quality indicators and low operational characteristics is an acute and urgent problem of the beet growing industry.

We have developed a new three-row top-harvesting machine that implements two-phase harvesting of sugar beet tops, which is aggregated with a wheeled tractor of traction class 1.4, equipped with a frontal power take-off shaft [9]. The topicality of determining the operational indicators of agricultural machines (and especially, new ones) is determined by their extreme importance for determining their profitability under real conditions of the farms, the possibility to assess the performance of work in the specified agricultural period, comparison with analogues. 
The purpose of the work is to determine the operational indicators (productivity, fuel consumption, power consumption) of a new experimental top-harvesting machine depending on the working speed, and to compare them with the most common analogue.

\section{Materials and methods}

The agrotechnical indicators of the plot of the field, on which the experimental studies were carried out, were as follows: the soil moisture $22.5 \%$; the soil hardness $2.0 \mathrm{MPa}$; the root crop yield $53.3 \mathrm{t} \cdot(\mathrm{ha})^{-1}$; the yield of tops $13.3 \mathrm{t} \cdot(\mathrm{ha})^{-1}$; the shape of the tops on the heads of the root crops by the nature of the placement of leaves: a rosette $21.1 \%$, a semi-socket $50.8 \%$, a cone $28.1 \%$.

To conduct experimental studies in order to determine the operational characteristics of the new top-harvesting machine, private methodologies were developed, and general methods were applied for conducting field tests of agricultural machines.

Field investigations of the experimental top-harvesting machine were carried out when it was aggregated with a MTZ-82.1 row-crop tractor, equipped with a frontal power take-off shaft. According to the existing methods, strain gauge sensors were glued to the main working bodies of the topharvesting machine, connected (via cable) to a mobile strain gauge station, which during the experimental investigations moved along the top-removing aggregate. The strain gauge sensors were glued to the driving shaft of the rotary top removing apparatus, the driving shaft of the auger conveyor with a loading thrower to the power take-off shaft, and also to the driving axle of the driving wheels of the aggregating tractor (to determine the traction resistance of the machine). This top removing machine was frontally (in front) mounted on the wheeled tractor, and it carried out continuous cutting of the entire mass of tops along its working width without extracting the root heads from the soil (it is supposed to install the working tools for digging the root crops as part of a combined aggregate) (Fig. 1).

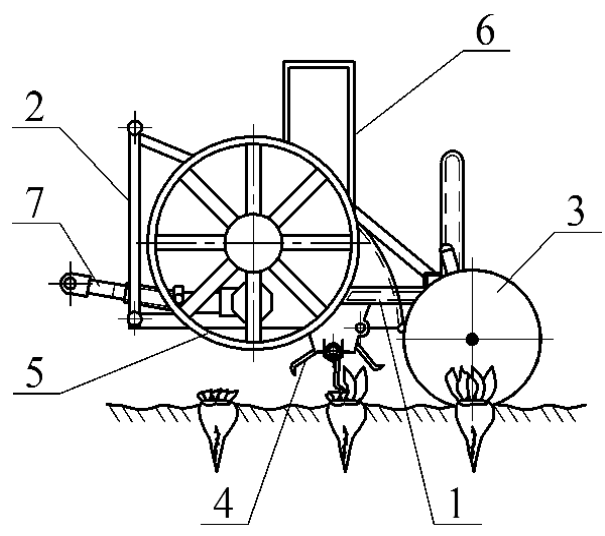

Fig. 1. Structural and technological scheme of the new top removing machine that we have developed, containing an improved rotary top cutting apparatus and a new loading device:

1 - frame; 2 - hitch attachment; 3 - supporting pneumatic copying wheel; 4 - rotary top cutting apparatus; 5 - transporting working tool; 6 - unloading device; 7 - power take-off shaft

The design peculiarities of this top removing machine are a continuous rotary top cutting apparatus, which provides cutting of the entire array of the tops with minimum energy consumption. The use of an auger conveyor for collecting the cut tops, transportation to the frontal part of the machine onto the blade loading mechanism (thrower), which, as a whole, also ensures simplicity of the design, minimal energy consumption and the lowest operating costs, provides high quality of the top removal from the sugar beet heads. The signal, received from the strain gauge sensors, made it possible to fix the torque and angular velocity on the drive shaft of the rotary top-cutting apparatus, the transporting auger and the blower. The other strain gauge sensors measured the traction resistance of the machine and the speed of its movement across the field. Other operational characteristics were recorded according to existing methodologies. The operational characteristics of the top-harvesting machine, recorded by us during the experimental investigations, were collected and processed on a PC. For statistical processing of the experimental data the "Data Analysis" package Microsoft Excel was used. The regression analysis, carried out with its help, was used to determine the dependences for 
the studied parameters, using the least squares method, according to which the coefficients of the regression equations are selected provided that the sums of the squared deviations of the found values from the actual values are minimal:

$$
\sum_{i=1}^{n}\left(y_{i}-y_{i r o z}\right)^{2}=\min
$$

We conduct approximation and smoothing of the obtained dependency graphs, using the trend line of a polynomial form in Excel with the approximation reliability $R^{2} \approx 1$ :

$$
R^{2}=1-\frac{\sum_{i=1}^{n}\left(y_{i}-\tilde{y}_{i}\right)^{2}}{\sum_{i=1}^{n} y_{i}^{2}-\frac{\left(\sum_{i=1}^{n} y_{i}\right)^{2}}{n}},
$$

where $y_{i}$-experimental value;

$\tilde{y}_{i}$ - expected mathematical value.

The larger this indicator, the better the resulting trend line describes the process under study. A detailed algorithm is given in [10]. As the resulting ones, it is necessary to obtain empirical dependences of the energy indicators upon the parameters of the top harvesting machine to adequately describe their impact. The energy parameters of the top-harvesting machine were taken during its study under the field conditions by measuring, using the strain gauge sensors in different modes of operation: for two different angular velocities $\left(\omega_{p o 1}=57 \mathrm{~s}^{-1}\right.$ and $\left.\omega_{p o 2}=39 \mathrm{~s}^{-1}\right)$ of the shaft of working bodies for transportation and loading the tops, as well as for the case, when their drive sprocket was switched off at all and, thus, the working bodies for transportation and loading were turned off $\left(\omega_{p o 3}=0\right)$, and only the cutting of the tops took place. Since the rotary top cutting apparatus performs cutting of the green mass without extracting the sugar beet heads from the soil without a support, it was established by our tests that the angular rotational velocities of the drive shaft should be not less than $40 \mathrm{~s}^{-1}$ (to exclude deviations of the tops during the unsupported cut) and not more than $60 \mathrm{~s}^{-1}$ (to prevent regrinding of the stems and leaves of the tops). The strain gauge equipment, used by us, accurately recorded the data of the angular velocities, which were equal, respectively, to $\omega_{p o 1}$ and $\omega_{p o 2}$.

\section{Results and discussion}

The field experimental studies, which were performed in triplicate for each mode of operation of the top-harvesting machine, made it possible to obtain full energy parameters [11], which are given in Table. 1.

Table 1

\begin{tabular}{|c|c|c|c|c|c|c|c|c|c|}
\hline \multirow{2}{*}{$\begin{array}{c}\text { Gears in } \\
\text { which the } \\
\text { tractor was } \\
\text { moving }\end{array}$} & $\begin{array}{c}v, \\
\mathbf{m} \cdot \mathbf{s}^{-1}\end{array}$ & $\begin{array}{c}N_{\text {PTO }} \\
\mathbf{k W}\end{array}$ & $\begin{array}{c}N, \\
\mathbf{k W}\end{array}$ & $\begin{array}{c}v, \\
\mathrm{~m} \cdot \mathrm{s}^{-1}\end{array}$ & $\begin{array}{c}N_{\text {PTO }}, \\
\mathbf{k W}\end{array}$ & $\begin{array}{l}N, \\
\mathbf{k W}\end{array}$ & $\begin{array}{c}v, \\
\mathrm{~m} \cdot \mathrm{s}^{-1}\end{array}$ & $\begin{array}{c}N_{\text {PTO }}, \\
\mathbf{k W}\end{array}$ & $\begin{array}{c}N, \\
\mathbf{k W}\end{array}$ \\
\hline & \multicolumn{3}{|c|}{$\omega_{p o 1}=57 \mathrm{~s}^{-1}$} & \multicolumn{3}{|c|}{$\omega_{p o 2}=39 \mathrm{~s}^{-1}$} & \multicolumn{3}{|c|}{$\omega_{p o 3}=0$} \\
\hline \multirow[t]{3}{*}{8} & 0.990 & 2.762 & 1.081 & 1.014 & 1.892 & 1. 261 & 1. 140 & 1.705 & 1.186 \\
\hline & 0.960 & 2.774 & 1. 194 & 1.146 & 2.387 & 1.367 & 1.236 & 2.148 & 1.632 \\
\hline & 0.954 & 2.884 & 8.720 & 1.176 & 2.297 & 1.582 & 1.314 & 2.409 & 1.468 \\
\hline \multirow{3}{*}{$\begin{array}{c}2 \\
\text { low }\end{array}$} & 1.464 & 3.835 & 2.119 & 1.698 & 3.478 & 2.673 & 1.692 & 3.043 & 2.492 \\
\hline & 1.380 & 3.836 & 2. 242 & 1.536 & 2.685 & 1.989 & 1.746 & 2. 289 & 2. 261 \\
\hline & 1.524 & 4.834 & 2.631 & 1.722 & 3.420 & 2.929 & 1.614 & 2.596 & 2.623 \\
\hline \multirow{3}{*}{2} & 2. 118 & 9.748 & 3.818 & 2. 124 & 6. 377 & 4. 476 & 2. 256 & 5.135 & 3.953 \\
\hline & 2.196 & 10.402 & 4.238 & 2.220 & 9.076 & 3.438 & 2.166 & 5.630 & 4.290 \\
\hline & 2.022 & 9.685 & 3.491 & 2.058 & 7.878 & 4. 024 & 2.148 & 4.742 & 3.763 \\
\hline
\end{tabular}

Results of investigation of the energy parameters of the prototype of the top-harvesting machine

$\omega_{p o 1}, \omega_{p o 2}$ and $\omega_{p o 3}$ are the calculated angular rotational velocity of the shaft, on which the working bodies for transportation and loading the cut tops are mounted. 
Based on the above methodology, to obtain data, linear and polynomial (in the form of polynomials of the second degree) empirical dependencies were determined. As a result of their analysis by the parameter $R^{2}$, polynomial dependencies were finally adopted, such as those that more accurately describe the nature of the data studied and correspond to the physical content of the phenomena. The graphically obtained dependences are presented in Fig. 2-4.

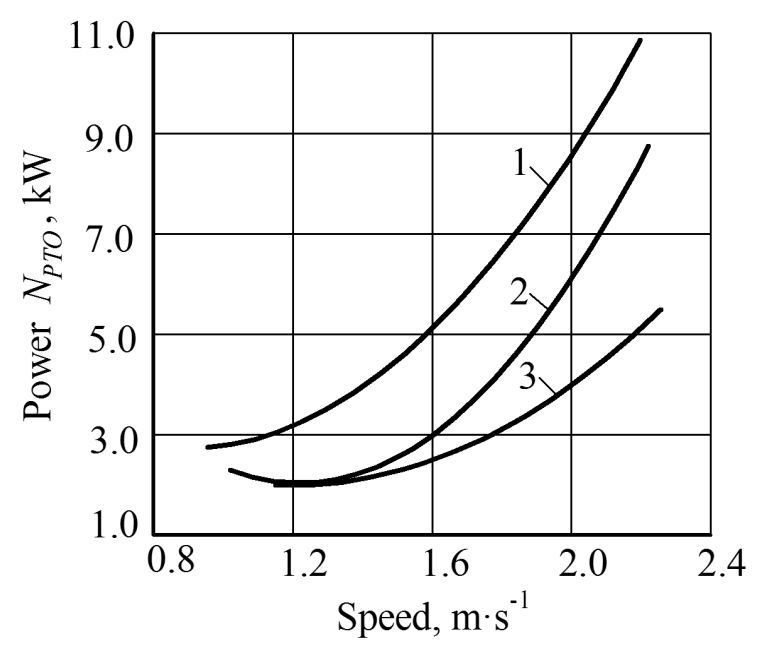

Fig. 2. Dependence of power on the drive of the working bodies of the top harvesting machine upon the speed of its forward motion: $1-\omega_{p o 1}=57 \mathrm{~s}^{-1}, 2-\omega_{p o 2}=39 \mathrm{~s}^{-1}, 3-\omega_{p o 3}=0$

As a result of the analysis of the obtained dependences of power upon the speed of the forward movement of the top-harvesting aggregate for different values of the angular velocity of the working bodies for transportation and loading the tops, it was established that the power needed to complete the entire technological process of harvesting tops within the range of the working speeds is $8.0-12.5 \mathrm{~kW}$. It increases with increasing the forward speed and reaches the maximum value of about $14.5 \mathrm{~kW}$ at a speed of $2.2 \mathrm{~m} \cdot \mathrm{s}^{-1}$.

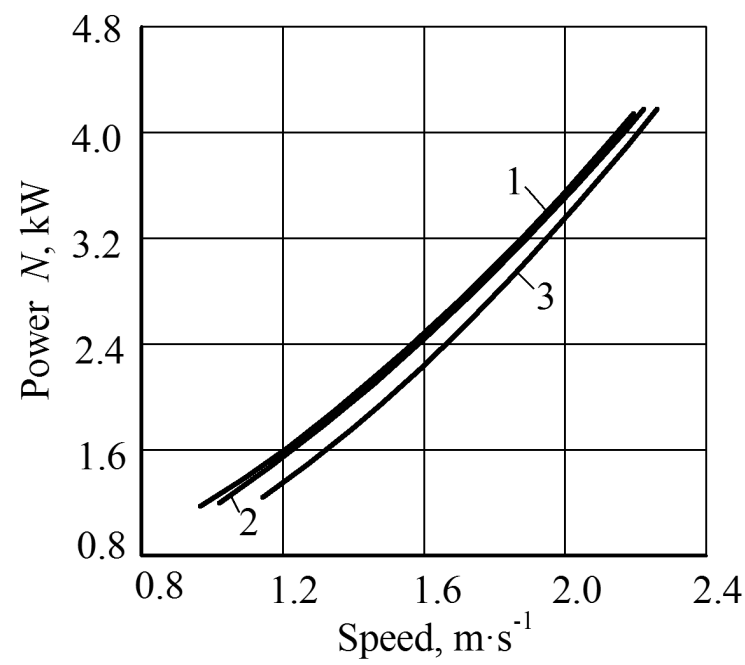

Fig. 3. Dependence of the traction power of the top harvesting machine on the speed of its movement: $1-\omega_{p o 1}=57 \mathrm{~s}^{-1}, 2-\omega_{p o 2}=39 \mathrm{~s}^{-1}, 3-\omega_{p o 3}=0$

The next step in the analysis of the experimental data was the construction of a mathematical model (regression equation) of the impact of variable factors upon the total power $N_{T}$ consumed by the top harvesting machine in the form:

$$
Y=f\left(X_{1}, X_{2}\right),
$$

where $X_{1}$ - forward speed of the top harvesting aggregate studied, $\mathrm{m} \cdot \mathrm{s}^{-1}$;

$X_{2}$ - angular velocity of rotation of the working bodies for transportation and loading of tops, $\mathrm{s}^{-1}$. 
The dependence that describes the change in the power consumption $N_{T}$, necessary for the operation of the top harvesting machine, is shown in Fig. 4, and written in the form of such regression equation:

$$
Y=-2.5655+6.5861 X_{1}+0.0707 X_{2} .
$$

Analysis of the obtained empirical dependences of the energy indicators of the top harvesting machine showed that their values will be minimal at a forward speed of $0.8-1.2 \mathrm{~m} \cdot \mathrm{s}^{-1}$, the lower values corresponding to a lower angular velocity of the drive shaft.

The energy indicators, obtained during the experimental investigations of the three-row design of the top harvesting machine that we have developed, indicate that its average reduced energy consumption is significantly lower than that of the existing and widely used harvesting machines in the world today. We recalculated the energy costs for 1 row width of the top removing machine, developed by us, and they are equal to $N_{P T O}=3.1 \mathrm{~kW}, N=1.4 \mathrm{~kW}$. It turned out that this is $1.2-1.5$ times less than the energy costs of the serial top removing machines, if they are calculated and brought to the single row width of the sugar beet plantation.

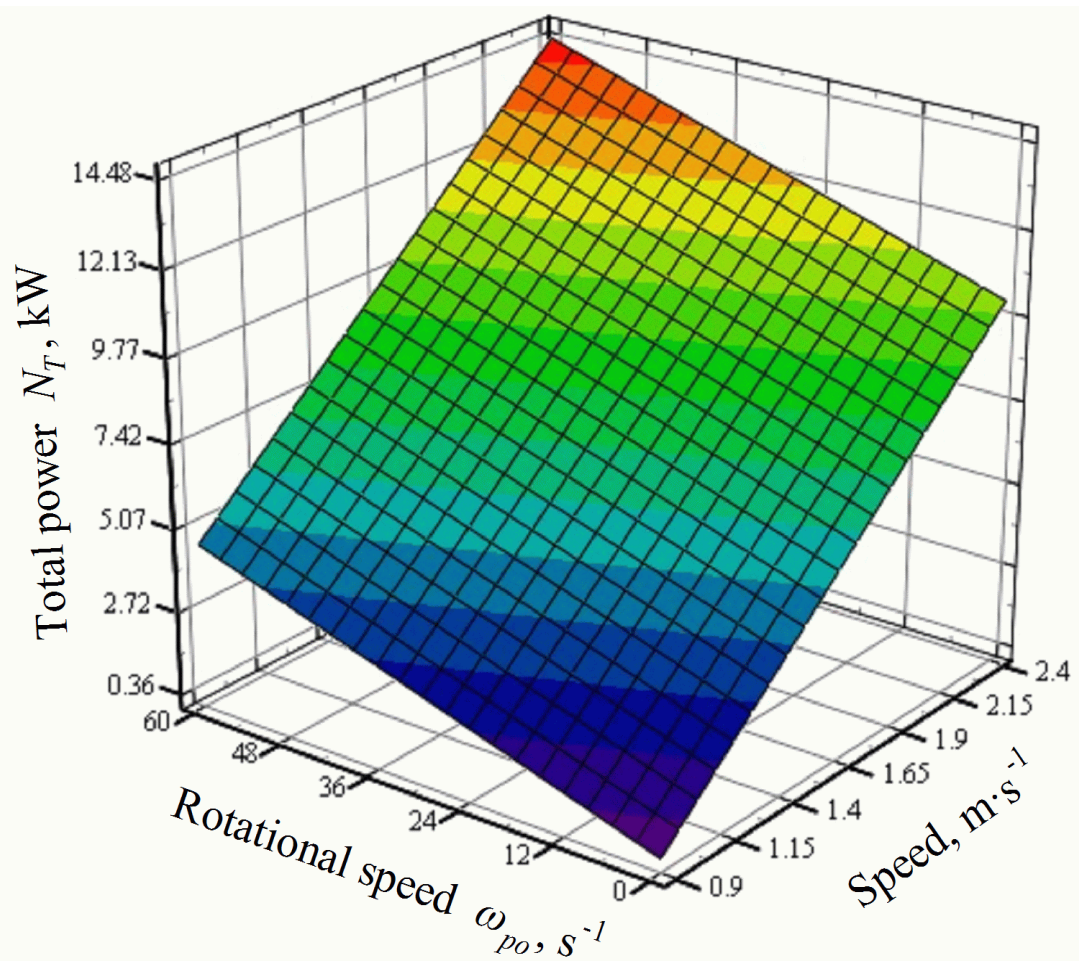

Fig. 4. Dependence of the total power consumption $N_{T}$ of the top harvesting machine upon the speed $v$ and the angular velocity of rotation of the working bodies for transportation and loading the tops $\omega_{p o}$

The power, determined by the results of the experimental field studies, which is needed to complete the entire technological process of harvesting the tops by the top harvesting machine, taking into account the drive efficiency, is about $14.48 \mathrm{~kW}$ at a forward speed of the topper of $1.2-2.2 \mathrm{~m} \cdot \mathrm{s}^{-1}$.

The operational and economic indicators of the new experimental machine, determined by the method [12], are given in Table 2.

Performance indicators of the compared top harvesting aggregates: the experimental top harvesting machine developed by us, and a commercially available one

\begin{tabular}{|c|c|c|}
\hline Indicator & Experimental machine & Serial machine \\
\hline Efficiency, ha $\cdot \mathrm{h}^{-1}$ & 2.15 & 1.63 \\
\hline Specific fuel consumption, $\mathrm{kg} \cdot \mathrm{ha}^{-1}$ & 3.02 & 5.58 \\
\hline Specific investments, USD $\cdot \mathrm{ha}^{-1}$ & 10.79 & 12.53 \\
\hline Reduced operating costs, $\mathrm{USD} \cdot \mathrm{ha}^{-1}$ & 16.34 & 22.10 \\
\hline
\end{tabular}


Due to lower energy costs for the implementation of the top harvesting process with an equal working width of the compared aggregates (Table 2), a decrease in the fuel consumption by $2.5 \mathrm{~kg} \cdot \mathrm{ha}^{-}$ ${ }^{1}$ is observed, as a result of which the operating costs are reduced by $5.8 \mathrm{USD} \cdot \mathrm{ha}^{-1}$.

\section{Conclusions}

1. Based on the results of the experimental field investigations, operational performance indicators of the new top harvesting machine are obtained. So, the efficiency, when aggregated with a class 1.4 wheeled tractor, is $2.15 \mathrm{ha} \cdot \mathrm{h}^{-1}$; the specific fuel consumption $-3.02 \mathrm{~kg} \cdot \mathrm{ha}^{-1}$; the specific investments $-10.79 \mathrm{USD} \cdot \mathrm{ha}^{-1}$; the reduced operating costs $-16.34 \mathrm{USD} \cdot \mathrm{ha}^{-1}$.

2. The total capacity for the execution of the entire technological process of the sugar beet top harvesting is $14.48 \mathrm{~kW}$. The maximum value of the traction power does not exceed $3.6 \mathrm{~kW}$ at the optimum speed of the forward movement. In addition, the power required to cut the tops is 6.0$6.2 \mathrm{~kW}$, and to ensure transportation and loading of the cut tops into the vehicle, the power of 3.5$4.8 \mathrm{~kW}$ is needed.

3. The operational indicators, obtained by the results of the experimental field investigations of the three-row top harvesting machine, developed by us, with a rotary top cutting apparatus, are 1.5-1.8 times less than the top harvesting machines of the same class of commercial output.

\section{References}

[1] Merkes R. 50 Jahre Prodaktionstechnik im Zuckerr. Benbau in Deutchland. Zuckerr., No 4, 2001, pp. 214-217.

[2] Vilde A. Development of technologies and machinery for production of sugar beet in Latvia. Proceedings of the conference "Safe and economical agricultural technologies" (25-26 July, 2002, Priekuli, Latvia), 2002. pp. 62-66.

[3] Погорелый Л.В., Татьянко Н.В., Свеклоуборочные машины (Beet Harvesting Machines). Киев: Техника, 2004, 232 p. (In Ukrainian).

[4] Bulgakov V., Ivanovs S., Ruzhylo Z., Golovach I. Theoretical investigations in cleaning sugar beet heads from remnants of leaves by cleaning blade. Engineering for Rural Development, Vol.15, 2016. pp. 1090-1097.

[5] Максаков В. Ботва, жом и мелисы при кормлении животных (The haulm, pulp and melissa when feeding animals). Киев: Урожай, 1993, 145p. (In Russian).

[6] Bulgakov V., Ivanovs S., Adamchuk V., Boris A. Mathematical model for determination of losses of sugar bearing-mass when sugar beet tops are removed. Engineering for Rural Development, Vol. 14, 2015, pp. 441-451.

[7] Игнатьев Е. И. Разработка новой конструктивно-технологической схемы уборки ботвы сахарной свеклы с использованием пахотно-пропашного трактора (Development of a new structural and technological scheme for harvesting sugar beet tops using arable and cultivating tractor), Вестник аграрной науки, 2016, № 8, pp. 67-71. (In Ukrainian).

[8] Мартыненко В. Механико-технологические основы повышения эффективности рабочих органов ботвоуборочных машин (Mechanic and technological foundations for increasing the efficiency of the working tools of the haulm removing machines). Ternopol, 2000, 33 p. (In Ukrainian).

[9] Bulgakov V., Adamchuk V., Ivanovs S., Ihnatiev Y. Theoretical investigation of aggregation of top removal machine frontally mounted on wheeled tractor. Engineering for Rural Development, Jelgava, 2017, Vol. 16. pp. 273-280.

[10]Веденяпин С.В. Общая методика экспериментальных исследований и обработки опытных данных, Москва: Колос, 1997, 159 р.

[11] Adamchuk V., Bulgakov V., Nadykto V, Ihnatiev Y., Olt J. Theoretical research into the power and energy performance of agricultural tractors. Agronomy Research. Volume 14, No 5, 2016, pp. 1511-1518.

[12]Методики економічного оцінювання техніки на етапі випробування: ДСТУ 4397:2005. (Methods of economic evaluation at the test stage. Ukrainian standard No 4397:2005), Киев, 2005. 16 c. (In Ukrainian). 